\title{
Efeito do lodo de esgoto e do nitrogênio nos fatores produtivos do girassol
}

\author{
${\text { Thomaz F. Lobo' }{ }^{1} \text {, Helio Grassi Filho', Leonardo T. Bull }{ }^{1} \text { \& Ana C. B. Kummer }}^{1}$
}

\section{RESUMO}

Dentre as diversas alternativas de disposição final de lodo de esgoto no Brasil, o uso agrícola se destaca por sua economicidade e adequação ambiental. Assim, o objetivo deste trabalho foi avaliar o efeito do lodo de esgoto compostado e do $\mathrm{N}$ nos parâmetros produtivos do girassol, após a sexta aplicação de lodo de esgoto em diferentes doses. O experimento foi conduzido na Fazenda Experimental São Manuel, SP, pertencente à Faculdade de Ciências Agronômicas da UNESP de Botucatu,SP. Foi adotado o delineamento experimental em blocos casualizados constituídos por 6 tratamentos e 4 repetições, assim definidos: T0 sem adubação nitrogenada; T1 - adubação química nitrogenada de acordo com a recomendação da cultura; T2 - 50\% adubação nitrogenada proveniente do lodo de esgoto e 50\% na forma mineral; T3 - 100\% adubação nitrogenada proveniente do lodo de esgoto; T4 - 150\% adubação nitrogenada proveniente do lodo de esgoto; T5 - 200\% adubação nitrogenada proveniente do lodo de esgoto. O aumento da dose de lodo de esgoto e o $\mathrm{N}$ proporcionaram um aumento no rendimento de grãos, de óleo e de matéria seca. $\mathrm{O}$ $\mathrm{N}$ influenciou no aumento de peso de mil grãos.

Palavras-chave: sustentabilidade, produtividade, rendimento de óleo

\section{Effect of sewage sludge and nitrogen on production factors of sunflower}

\begin{abstract}
In Brazil, among the various alternatives for final disposal of sewage sludge, agricultural use is notable for its economy and environmental compatibility. The objective of this study was to evaluate the effect of composted sewage sludge and $\mathrm{N}$ parameters on sunflower production after the sixth application of sewage sludge in different doses. The experiment was conducted at the Experimental Farm São Manuel-SP, belonging to the Faculty of Agronomic Sciences, UNESP, Botucatu-SP. The experimental design adopted was randomized blocks, consisting of six treatments and four replications defined as follows: T0 - without nitrogen fertilization; $\mathrm{T} 1$ - chemical nitrogen fertilizer in accordance with the recommendation for the crop; $\mathrm{T} 2-50 \%$ nitrogen derived from sewage sludge and $50 \%$ in mineral form; $\mathrm{T} 3-100 \%$ nitrogen from sewage sludge; T4 - 150\% nitrogen from sewage sludge; T5 - 200\% nitrogen from sewage sludge. Increasing the dose of sewage sludge and $\mathrm{N}$ provided an increase in grain yield, oil and dry matter. The $\mathrm{N}$ influenced the increase in the weight of thousand grans.
\end{abstract}

Key words: sustainability, productivity and oil of yield 


\section{INTRODUÇÃO}

No Brasil, a disposição final do lodo de esgoto geralmente é o aterro sanitário. Além do alto custo, que pode chegar a $50 \%$ do custo operacional de uma estação de tratamento de esgoto (ETE), a disposição de um resíduo com elevada carga orgânica no aterro agrava ainda mais o problema com o manejo do lixo urbano. Em países da Europa e América do Norte, em geral o lodo é incinerado e depositado em aterros sanitários ou utilizado em áreas agrícolas dependendo das características do resíduo. $\mathrm{Na}$ maioria dos países existem normas que regulamentam o destino do lodo garantindo uma disposição segura. A adição ao solo parece ser a melhor opção do ponto de vista econômico e ambiental uma vez que apresenta o menor custo e promove a reciclagem de matéria orgânica e nutrientes (Betiol \& Camargo, 2007).

Existem muitos resíduos orgânicos de origem urbana, industrial e agrícola, que podem ser usados na agricultura (Melo et al., 2008).

Além de eliminar grande parte dos patógenos (Correa et al., 2007) o lodo de esgoto compostado apresenta uma matéria orgânica mais estabilizada, devido aos baixos teores de nutrientes e baixas taxas de mineralização em solos (TerhovenUselamans et al., 2009; Trannin et al., 2008).

Resíduos orgânicos devem ser estabilizados para serem utilizados de maneira segura (Plachá et al., 2008) significando que a matéria orgânica original deve ser convertida para uma forma mais resistente à degradação e, consequentemente, menos mineralizável (Rathod et al., 2009).

Diversos trabalhos demonstram aumentos na produção de matéria seca e de grãos por espécies de interesse agronômico, cultivados em solos tratados com lodo de esgoto. Em alguns casos os aumentos são equiparáveis ou superiores aos obtidos com a adubação mineral recomendada para a cultura (Gomes et al., 2007; Barbosa et al., 2007) e produção de mudas de pinhão-manso (Camargo et al., 2010).

Apesar disto, a complementação potássica é apontada frequentemente como imprescindível para a obtenção de boas produções (Silva et al., 2001) uma vez que o resíduo é pobre neste elemento.

A incorporação de altas doses de matéria orgânica tem sido a solução mais comum e tem contribuído, sobremaneira, para elevar a fertilidade do solo, cria condições favoráveis às plantas, aos organismos do solo e ao restabelecimento de ciclos biogeoquímicos no local a ser revegetado (Adani et al., 2007; Rodrigues et al., 2007).

O girassol é uma cultura com grande capacidade de produção de matéria seca e acúmulo de nutrientes. O girassol, por apresentar índices de colheita e de exportação de nutrientes reduzidos, folhas e capítulos com taxa de decomposição elevada e sistema radicular profundo, favorece uma rápida ciclagem de nutrientes ao longo do perfil de solo e possibilita um desenvolvimento melhor das culturas subsequentes (Castro et al., 2005).
Avaliações experimentais indicam que a produção máxima de girassol é alcançada com 80 a $90 \mathrm{~kg} \mathrm{ha}^{-1} \mathrm{de} \mathrm{N}$; contudo, com aplicação de 40 a $50 \mathrm{~kg} \mathrm{ha}^{-1}$ de N se obtém $90 \%$ da produção relativa máxima, correspondendo à quantidade do nutriente economicamente mais eficiente (Smiderle et al., 2002).

O objetivo deste trabalho foi, portanto, avaliar o efeito do lodo de esgoto e do $\mathrm{N}$ nos parâmetros produtivos do girassol com diferentes manejos de aplicação de lodo de esgoto e $\mathrm{N}$ mineral após a aplicação de seis cultivos em rotações de culturas.

\section{Material e Métodos}

O estudo foi conduzido na Fazenda Experimental São Manuel pertencente à Faculdade de Ciências Agronômicas da UNESP de Botucatu, SP, localizada no município de São Manuel, SP, a $22^{\circ} 25^{\prime}$ Latitude Sul, $48^{\circ} 34^{\prime}$ Longitude Oeste, com altitude de $750 \mathrm{~m}$.

A área de instalação do experimento vinha sendo manejada há quatro anos com lodo de esgoto em sistema de rotação de culturas. Foi adotado o delineamento experimental em blocos casualizados constituídos por 6 tratamentos e 4 repetições, assim definidos: T0 - sem adubação nitrogenada; T1 - adubação química nitrogenada de acordo com Raij et al. (1997); T2 - 50\% adubação nitrogenada proveniente do lodo de esgoto e $50 \%$ na forma mineral; T3 - 100\% adubação nitrogenada proveniente do lodo de esgoto; $\mathrm{T} 4-150 \%$ adubação nitrogenada proveniente do lodo de esgoto; T5 - 200\% adubação nitrogenada proveniente do lodo de esgoto. Cada parcela apresentou uma área de aproximadamente $100 \mathrm{~m}$ quadrados $(14 \times 7,2 \mathrm{~m}) \mathrm{com}$ espaço de $3 \mathrm{~m}$ entre parcelas do mesmo bloco. $\mathrm{O}$ espaço de um bloco a outro foi de $1,8 \mathrm{~m}$.

Neste estudo foi utilizado um lodo de esgoto compostado com bagaço de cana. A finalidade de ter sido utilizado o lodo compostado foi a eliminação dos patógenos presentes no lodo com o aumento da temperatura na compostagem. As características químicas do composto de lodo de esgoto utilizado no experimento estão na Tabela 1.

Antes da semeadura do girassol aplicou-se o Gliphosathe (ia) na dosagem de $2 \mathrm{~L} \mathrm{ha}^{-1}$ juntamente com o ácido bórico (17\% B), na dosagem de $6 \mathrm{~kg} \mathrm{ha}^{-1}$, em um volume de calda de $320 \mathrm{~L}$ $\mathrm{ha}^{-1}$ visando ao controle de plantas daninhas e fornecimento de Boro para a cultura, elemento imprescindível para o girassol. Após uma semana da aplicação a área foi roçada e a aplicação do composto nos tratamentos se deu através de um distribuidor de esterco, nas dosagens apresentadas na Tabela 2.

Em dezembro de 2008 foi semeado o girassol, cultivar HELIO 251, fornecida pela empresa Helianthus do Brasil, que apresenta as seguintes características: híbrido simples, com ciclo de 90 a 115 dias, tolerante às doenças - Ferrugem Preta, Podridão de raízes e Verticilium, ótima resistência a acamamento, altura média da planta de 1,70 a 2,10 $\mathrm{m}$ densidade de colheita 40.000 plantas ha ${ }^{-1}$, teor de óleo de 40 a $44 \%$, recomendado para todo o Brasil.

Tabela 1. Análises químicas do lodo de esgoto compostado com bagaço de cana

\begin{tabular}{|c|c|c|c|c|c|c|c|c|c|c|c|c|c|c|c|}
\hline $\mathbf{N}$ & $\mathbf{P}_{2} \mathbf{O}_{5}$ & $\mathrm{~K}_{2} \mathrm{O}$ & Umid. & MO & C & $\mathrm{Ca}$ & $\mathrm{Mg}$ & $S$ & $\mathrm{Na}$ & $\mathrm{Cu}$ & $\mathrm{Fe}$ & Mn & $\mathrm{Zn}$ & $\mathrm{C} / \mathrm{N}$ & $\mathrm{pH}$ \\
\hline \multicolumn{9}{|c|}{$\%$ na matéria seca } & \multicolumn{7}{|c|}{$\mathrm{mg} \mathrm{kg}^{-1}$ na matéria seca } \\
\hline 2,44 & 2,0 & 0,4 & 58 & 53 & 29,4 & 1,9 & 0,3 & 1,6 & 1340 & 304 & 23250 & 472 & 3750 & $12 / 1$ & 6,6 \\
\hline
\end{tabular}


Tabela 2. Quantidade do composto aplicado no girassol

\begin{tabular}{rrrrr}
\hline \multirow{2}{*}{ Trat. } & \multicolumn{2}{c}{ Quantidade - base } & Quantidade & $\begin{array}{c}\text { Quantidade de N } \\
\text { mineralizado (30\%) }\end{array}$ \\
\cline { 2 - 4 } & Úmida & Seca & de N & \\
\cline { 2 - 4 } T2 & & & $\mathbf{k g}^{-1}$ & \\
T2 & 8.768 & $3.682,6$ & 89,85 & 26,9 \\
T3 & 17.536 & $7.365,1$ & 179,71 & 53,9 \\
T4 & 26.305 & $11.047,6$ & 269,60 & 80,9 \\
T5 & 35.073 & $14.730,2$ & 359,40 & 107,8 \\
\hline
\end{tabular}

A semeadura se deu na profundidade de $3 \mathrm{~cm}$ com espaçamento de $0,7 \mathrm{~m}$ entre linha e 3,5 sementes por metro, totalizando um estande de 50.000 plantas ha $^{-1}$. A adubação de semeadura para todas as parcelas foi constituída de $51 \mathrm{~kg} \mathrm{ha}^{-1}$ de $\mathrm{P}_{2} \mathrm{O}_{5}$ na forma de superfosfato simples $\left(170 \mathrm{~g} \mathrm{~kg}^{-1} \mathrm{P}_{2} \mathrm{O}_{5}\right) \mathrm{e}$ $30,5 \mathrm{~kg} \mathrm{ha}^{-1}$ de $\mathrm{K}_{2} \mathrm{O}$ na forma de cloreto de potássio $\left(600 \mathrm{~g} \mathrm{~kg}^{-1}\right.$ $\mathrm{K}_{2} \mathrm{O}$ ). Parte da adubação de $\mathrm{N}$ mineral foi realizada 12 dias após a semeadura no T1, na dosagem de $10 \mathrm{~kg} \mathrm{ha}^{-1} \mathrm{de} \mathrm{N}$ na forma de uréia ( $\left.450 \mathrm{~g} \mathrm{~kg}^{-1} \mathrm{de} \mathrm{N}\right)$, na fase em que o girassol começou a emergir. Os tratamentos T0, T2, T3, T4 e T5 não receberam adubação com $\mathrm{N}$, nessa ocasião.

A adubação de cobertura foi realizada nos tratamentos T1 e T2 (40 e $25 \mathrm{~kg} \mathrm{ha}^{-1}$ de $\mathrm{N}$, respectivamente) nas doses recomendadas para o estado de São Paulo, de acordo com o Boletim 100 (Raij et al., 1997). Ressalta-se que os outros $25 \mathrm{~kg}$ $\mathrm{ha}^{-1}$ de N, do T2, foram aplicados antes da semeadura na forma de lodo de esgoto totalizando os $50 \mathrm{~kg} \mathrm{ha}^{-1}$. A fonte utilizada para a cobertura foi a uréia, operação executada aos 30 dias após a emergência.

Aos 40 dias da semeadura realizou-se um controle com herbicida (Paraquat dicloreto), com jato dirigido na entre linha e chapéu de napoleão na dosagem de $70 \mathrm{~mL}$ em $20 \mathrm{~L}$ de água, em um volume de calda de $200 \mathrm{~L} \mathrm{ha}^{-1}$.

A colheita foi realizada aos 117 dias após a semeadura quando os capítulos do girassol já estavam todos voltados para baixo. Na fase de florescimento foram cobertos 20 capítulos ao acaso, por parcela, para evitar problemas com pássaros. Desses 20 capítulos foram colhidos, ao acaso, 10 capítulos por parcela para determinar a produção. As folhas e os caules dessas plantas foram utilizados para determinar a produtividade de matéria seca. Em seguida foram colocados folhas, caule e capítulo em estufa a $60^{\circ} \mathrm{C}$ até massa constante. Os grãos foram separados dos capítulos, manualmente. A massa de mil grãos foi determinada segundo metodologia de Brasil (2001).

Nos grãos foram avaliados os seguintes parâmetros: o peso das sementes com umidade corrigida a $11 \%$, massa de mil sementes e o teor e rendimento de óleo, que foi calculado multiplicando-se o teor com a produtividade.

O teor de óleo nas sementes de girassol foi determinado por RMN (Ressonância Magnética Nuclear) em baixa resolução, segundo metodologia descrita por Prestes et al. (2007).

Todos os resultados foram submetidos à análise de variância e as médias comparadas pelo teste de Duncan a 0,05 de significância. Nos tratamentos T0, T3, T4 e T5, que sofreram o aumento da dose de lodo, foi efetuada uma regressão para os parâmetros em que houve diferença significativa no teste de média.

\section{Resultados e Discussão}

Os resultados de rendimento de grãos (Tabela 3) mostram que o T5, no qual foram utilizados $200 \%$ de adubação nitrogenada proveniente do lodo de esgoto, apresentou maior valor quando comparado com os demais tratamentos, seguido do T2. Desta maneira observa-se, com o aumento da dose de lodo compostado, um incremento linear, para cada tonelada de lodo, o que aumentou $76 \mathrm{~kg}$ de rendimento de grão no rendimento de grãos (Figura 1A). Lobo \& Grassi Filho (2007) obtiveram, trabalhando com lodo de esgoto, rendimento de grãos de girassol semelhante ao apresentado neste trabalho, tendo encontrado maior valor para os tratamentos que receberam $50 \%$ do $\mathrm{N}$ mineral combinado com $50 \%$ de lodo de esgoto e o tratamento de $200 \%$ de lodo de esgoto.

Tabela 3. Rendimento de grão, massa de 1000 grãos, teor de óleo e rendimento de óleo no girassol

\begin{tabular}{ccccc}
\hline Tratamento & $\begin{array}{c}\text { Rendimento } \\
\text { de grãos } \\
\mathbf{( k g ~ h a}^{-1} \mathbf{)}\end{array}$ & $\begin{array}{c}\text { Massa de } \\
\mathbf{1 0 0 0} \text { grãos } \\
\mathbf{( g )}\end{array}$ & $\begin{array}{c}\text { Teor } \\
\text { de óleo } \\
\mathbf{( \% )}\end{array}$ & $\begin{array}{c}\text { Rendimento } \\
\text { de óleo } \\
\mathbf{( k g ~ h a ~}^{-1} \mathbf{)}\end{array}$ \\
T0 & $2.074 \mathrm{e}$ & $56,12 \mathrm{~b}$ & $34,6 \mathrm{ab}$ & $718,5 \mathrm{C}$ \\
T1 & $3.760 \mathrm{~cd}$ & $74,46 \mathrm{a}$ & $35,6 \mathrm{a}$ & $1.340,1 \mathrm{ab}$ \\
T2 & $4.524 \mathrm{ab}$ & $73,39 \mathrm{a}$ & $34,7 \mathrm{ab}$ & $1.568,1 \mathrm{a}$ \\
T3 & $3.158 \mathrm{~d}$ & $72,81 \mathrm{a}$ & $34,9 \mathrm{ab}$ & $1.101,8 \mathrm{~b}$ \\
T4 & $4.009 \mathrm{bc}$ & $79,52 \mathrm{a}$ & $33,7 \mathrm{~b}$ & $1.349,8 \mathrm{ab}$ \\
T5 & $4.767 \mathrm{a}$ & $78,48 \mathrm{a}$ & $33,4 \mathrm{~b}$ & $1.597,6 \mathrm{a}$ \\
\hline F & $16,53^{*}$ & $7,87^{\star}$ & $2,33^{*}$ & $14,82^{*}$ \\
Média & 3.715 & 72,46 & 34,50 & $1.279,30$ \\
C.V. (\%) & 13,04 & 8,33 & 3,04 & 13,33 \\
\hline
\end{tabular}

Médias seguidas pelas mesmas letras na coluna não diferem entre si pelo teste de Duncan, a $0,05$ de probabilidade; * Significativos a 0,05 ( $p>0,05)$

Resultados de produtividade na cultura do girassol em trabalho realizado por Dechamps \& Favoretto (1997) os autores mostraram que o lodo de esgoto pode ser utilizado como fonte de adubação orgânica substituindo $100 \%$ a quantidade de $\mathrm{N}$ recomendada, sem prejuízo em termos de rendimento quando comparado com a adubação mineral.

A quantidade de aplicação do composto no girassol (Tabela 2) não afetou negativamente o rendimento da cultura tendo em vista que os melhores valores foram observados nos Tratamentos 4 e 5 , nos quais foram aplicados, respectivamente, 80,9 e $107,8 \mathrm{~kg} \mathrm{ha}^{-1}$ de N (mineralizado). Bovi et al. (2007) observaram que a mineralização do $\mathrm{N}$ orgânico é proporcional à dose aplicada no solo.

Para a massa de mil grãos somente o tratamento em que não foi aplicado $\mathrm{N}$ foi inferior aos demais tratamentos, ou seja, o $\mathrm{N}$ interferiu no peso de mil sementes de girassol (Tabela 3). Biscaro et al. (2008) observaram que houve efeito positivo no peso de 100 aquênios em decorrência da aplicação de $\mathrm{N}$ até a dose de 44,9 $\mathrm{kg}$ de $\mathrm{N} \mathrm{ha}^{-1}$ alcançando 7,19 g. O aumento da dose de lodo compostado proporcionou aumento na massa de mil sementes (Figura 1B).

Observa-se, na Tabela 3, que o teor de óleo foi superior onde se aplicaram 100\% de N mineral (T1) em relação aos T4 e T5, com a aplicação de 150 e $200 \%$ de $\mathrm{N}$ de lodo compostado, respectivamente. $\mathrm{O}$ aumento da dose de lodo proporcionou um pequeno incremento no teor de óleo e decréscimo acentuado de forma quadrática, como mostra a Figura 2C. Lobo \& Grassi Filho 
A.

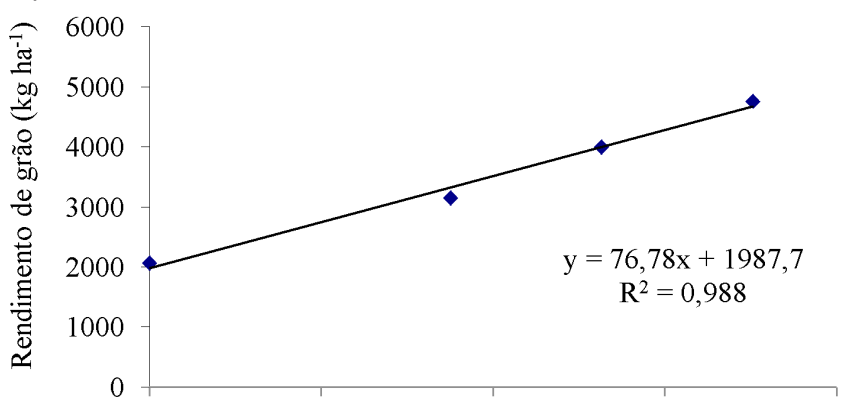

B.

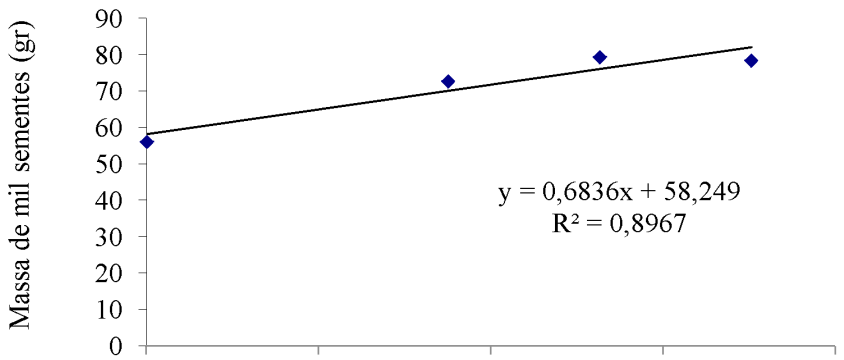

C.

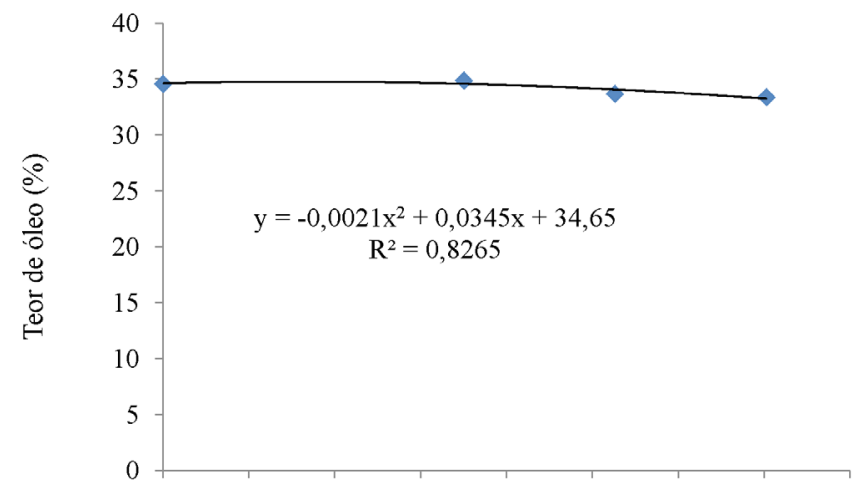

D.

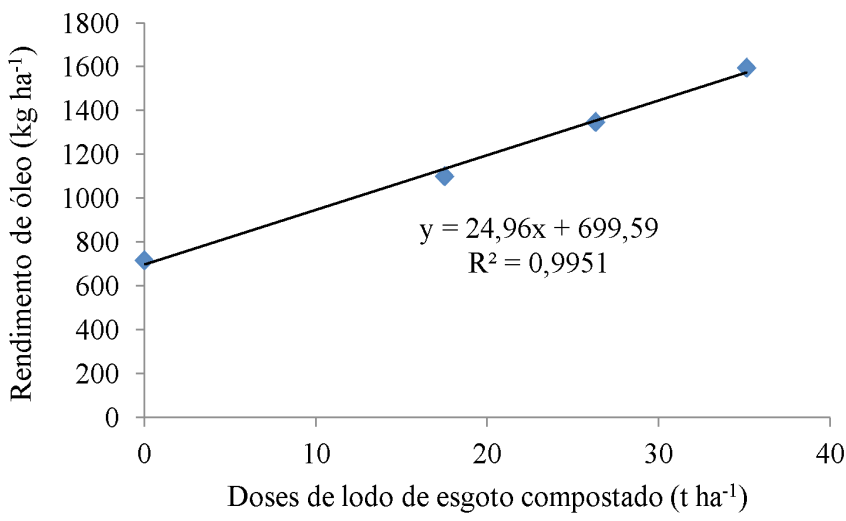

Figura 1. Curvas de regressão para o rendimento de grãos (A), massa de 1000 sementes (B), teor de óleo (C) e rendimento de óleo (D) da cultura do girassol, em função da dose de lodo compostado

(2007) obtiveram valores do teor de óleo em tratamentos com lodo de esgoto superiores aos resultados observados neste ensaio porém não houve variação entre os tratamentos. Souza et al. (2010) concluíram que o esgoto doméstico tratado obteve menor teor de óleo em relação à adubação recomendada da mamona.

Para o rendimento de óleo em $\mathrm{kg} \mathrm{ha}^{-1}$ verificou-se que os tratamentos com aplicação de $200 \%$ de N proveniente do lodo de esgoto compostado e $50 \%$ de $\mathrm{N}$ de lodo compostado combinado com $50 \%$ de $\mathrm{N}$ mineral se apresentaram superiores ao tratamento com $100 \%$ de lodo compostado. O tratamento que não recebeu $\mathrm{N}$ (T0) apresentou valores inferiores aos dos demais tratamentos. Observa-se, na Figura $1 \mathrm{D}$, que com o aumento da dose de lodo ocorreu aumento linear no rendimento de óleo.

Levando em consideração a grande importância do rendimento de óleo para as agroindústrias, conclui-se que existe a perspectiva de que a produção de girassol seja remunerada por esta qualidade em razão de que as recomendações de $\mathrm{N}$ para a cultura não são muito elevadas. Observa-se, na Figura $1 \mathrm{D}$, que com o aumento da dose de lodo ocorreu aumento linear no rendimento de óleo; entretanto, não foi verificada diferença nos teores de óleo entre os tratamentos (Tabela 3).

$\mathrm{Na}$ Tabela 4 são apresentados os rendimentos de massa seca da cultura do girassol.

Tabela 4. Rendimento de matéria seca (MS) do girassol

\begin{tabular}{ccccc}
\hline \multirow{2}{*}{ Tratamentos } & MS capítulo & MS caule & MS folha & MS total \\
\cline { 2 - 5 } & \multicolumn{4}{c}{$\mathbf{k g ~ h a}^{-1}$} \\
T0 & $1.045,9 \mathrm{C}$ & $912,1 \mathrm{~d}$ & $383,9 \mathrm{~d}$ & $2.339 \mathrm{~d}$ \\
T1 & $1.808,1 \mathrm{~b}$ & $2.014,1 \mathrm{~b}$ & $1.036,9 \mathrm{bc}$ & $4.859 \mathrm{~b}$ \\
T2 & $2.225,7 \mathrm{a}$ & $2.100,4 \mathrm{~b}$ & $1.149,5 \mathrm{ab}$ & $5.476 \mathrm{ab}$ \\
T3 & $1.740,3 \mathrm{~b}$ & $1.407,2 \mathrm{C}$ & $758,2 \mathrm{C}$ & $3.906 \mathrm{C}$ \\
T4 & $2.063,4 \mathrm{ab}$ & $1.975,3 \mathrm{~b}$ & $1.036,1 \mathrm{bc}$ & $5.075 \mathrm{~b}$ \\
T5 & $2,206,1 \mathrm{a}$ & $2.538,6 \mathrm{a}$ & $1.398,9 \mathrm{a}$ & $6.144 \mathrm{a}$ \\
\hline F & $15,70^{*}$ & $17,44^{*}$ & $13,16^{*}$ & $20,64^{*}$ \\
Média & $1.848,20$ & $1.824,60$ & 960,60 & $4.633,40$ \\
CV & 12,05 & 15,08 & 20,09 & 12,77 \\
\hline Médias seguidas pelas mesmas letras na coluna não diferem entre si pelo teste de Duncan, a \\
0,05 de probabilidade; * Significativos a 0,05 ( $\mathrm{p}>0,05) ;$ MS = Massa Seca
\end{tabular}

Para o rendimento de matéria seca total o tratamento 5 foi superior aos demais tratamentos; o T0, que não recebeu $\mathrm{N}$, foi inferior a todos (Tabela 4). Na Figura 2 observa-se que o rendimento de matéria seca no caule, na folha, no capítulo e total, mostrou uma resposta significativa ao aumento do composto de lodo de esgoto aplicado.

Esses parâmetros de rendimento de matéria seca estão intimamente associados à quantidade de $\mathrm{N}$ colocado à disposição da planta (Malavolta et al., 1997). Araújo et al. (2009) que encontraram correlações positivas entre os aumentos nas doses de lodo e produtividade de matéria seca em Braquiaria Decumbens. Barbosa et al. (2007) observaram, em milho safrinha, uma produtividade maior de matéria seca, em função do lodo de esgoto. Oliveira et al. (2009) obtiveram aumento de matéria seca de mamona com a aplicação de lodo de esgoto.

Verificando a média dos tratamentos (Tabela 4) concluise que cerca de $40 \%$ da matéria seca total foram do caule da planta e $60 \%$, folha e capítulo. Este parâmetro de rendimento médio de matéria seca é de fundamental importância tendo em vista que essas partes da planta (capítulo, caule e folha) podem retornar ao solo trazendo benefícios às plantas subsequentes contribuindo com uma retenção maior de umidade no solo e melhor disponibilidade de nutrientes, visto que no girassol a decomposição da folha e do capítulo é rápida, por apresentar baixa relação $\mathrm{C} / \mathrm{N}$. A decomposição do caule é mais lenta haja vista apresentar alta relação $\mathrm{C} / \mathrm{N}$. Esta diferença no tempo de decomposição é interessante pois as partes que se decompõem rapidamente fornecem nutrientes para a próxima cultura 
A.

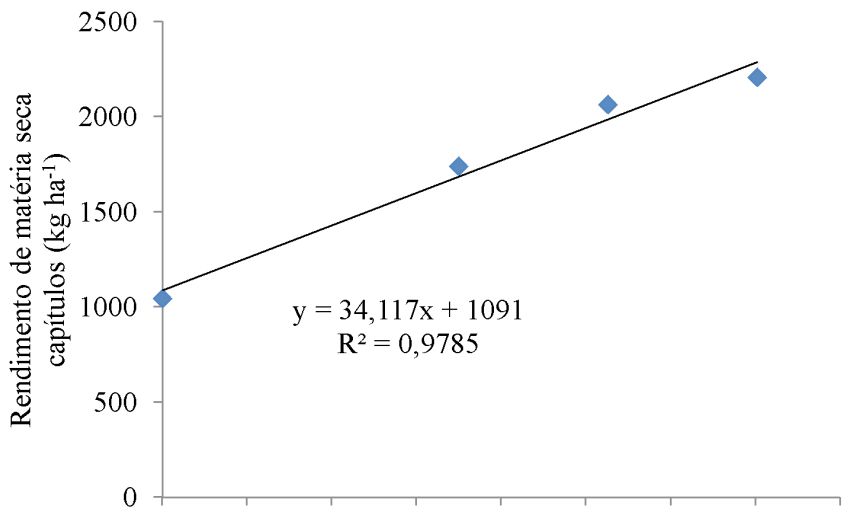

B.

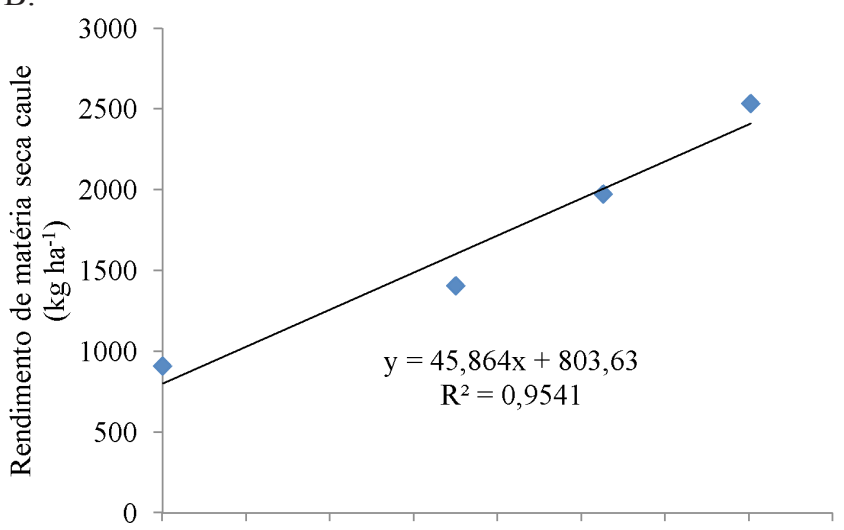

C.

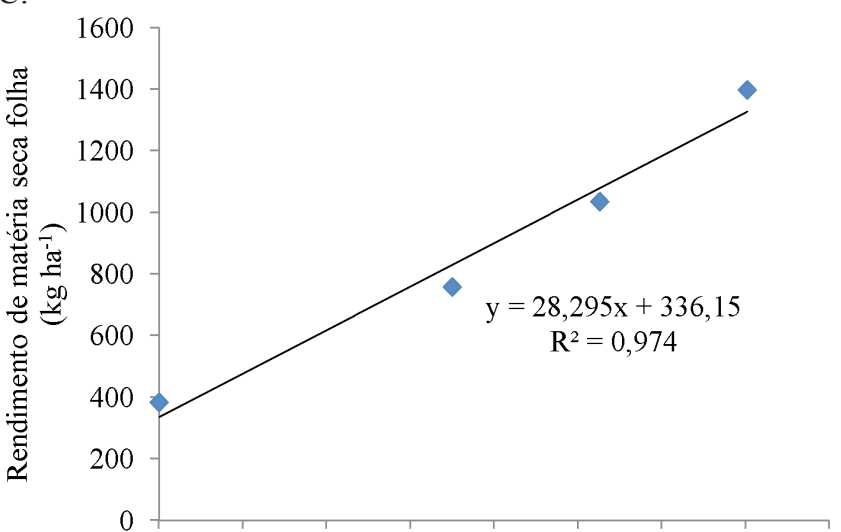

D.

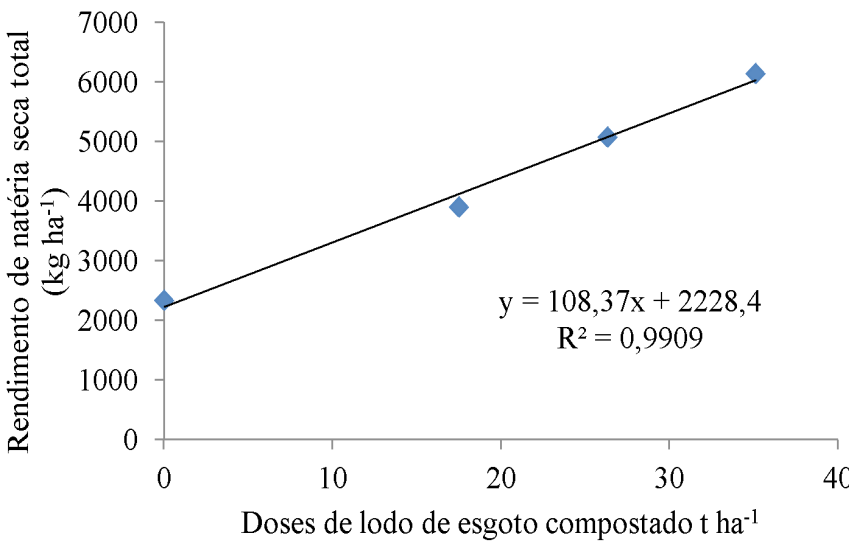

Figura 2. Curvas de regressão para o rendimento de matéria seca do capítulo (A), do caule (B), da folha (C) e matéria seca total (D) em função da dose de lodo compostado enquanto, por outro lado, a outra parte permanecerá mais tempo no solo favorecendo a retenção de umidade e protegendo o solo.

\section{Conclusões}

1. O aumento da dose de lodo de esgoto e o N proporcionaram um aumento no rendimento de grãos, rendimento de óleo, peso de 1000 sementes e rendimento de matéria seca do girassol.

2. Conforme se aumentaram as doses de lodo e, consequentemente, de $\mathrm{N}$, houve incremento no teor de óleo seguido de decréscimo acentuado nos seus valores.

\section{Agradecimentos}

À CAPES, pela bolsa de doutorado concedida ao primeiro autor.

\section{Literatura Citada}

Adani, F.; Genevini, P.; Ricca, R.; Tambone, F.; Montoneri, E. Modification of soil humic matter after 4 year of compost application. Waste Management, v.27, p.319-324, 2007.

Araújo, F. F.; Gill, F. C.; Tiritan, C. S. Lodo de esgoto na fertilidade do solo na nutrição da Brachiaria decumbens e na atividade da desidrogenase. Pesquisa Agropecuária Tropical, v.39, p.1-6, 2009.

Barbosa, G. M. C.; Tavares Filho, J.; Brito, O. R.; Fonseca, I. C. Efeito residual do lodo de esgoto na produtividade do milho safrinha. Revista Brasileira de Ciência do Solo, v.31, p.601-605, 2007.

Betiol, W.; Camargo, O. A. Lodo de esgoto na agricultura: Potencial de uso e problemas. Belo Horizonte: TEC Hoje, 2007. p.1-4.

Biscaro, G. A.; Machado, O. J. R.; Tosta, M. da S.; Mendonça, V.; Soratto, R. P.; Carvalho, L. A. de Adubação nitrogenada em cobertura no girassol irrigado nas condições de Cassilandia - MS. Ciência e Agrotecnologia, v.32, p.13661373, 2008.

Bovi, M. L. A.; Goday Júnior, R. G.; Costa, E. A. D. da; Berton, R. S.; Spiering, S. H.; Vega, F. V. A.; Cembranelli, M. A. R.; Maldonado, C. A. B. Lodo de esgoto e produção de palmito em pupunheira. Revista Brasileira de Ciência do Solo, v.31, p.153-166, 2007.

Brasil. Ministério da Agricultura e Reforma Agrária. Regras para análise de sementes. Brasília: MARA, 2001. 395p.

Camargo, R. de; Maldonado, A. C. D.; Silva, P. A.; Costa, T. R. da. Biossólido como substrato na produção de mudas de pinhão-manso. Revista Brasileira Engenharia Agrícola e Ambiental, v.14, p.1304-1310, 2010.

Castro, C.; Oliveira, F. A. de; Veronesi, C. O.; Salinet, L. H. Acúmulo de matéria seca, exportação e ciclagem de nutrientes pelo girassol. In Reunião Nacional de Pesquisa de Girassol, 16, 2005, Londrina. Anais... Londrina: Embrapa CNPSo, 2005. p-29-31.

Correa, R. S.; Fonseca, Y. M. F.; Correa, A. S. Produção de biossólido agrícola por meio da compostagem e vermicompostagem de lodo de esgoto. Revista Brasileira Engenharia Agrícola Ambiental, v.11, p.420-426, 2007. 
Deschamps, C.; Favoretto, N. Efeito do lodo de esgoto complementado com fertilizante mineral na produtividade e desenvolvimento da cultura do feijoeiro e do girassol. Sanare, v.8, p.33-38, 1997.

Gomes, S. B. V.; Nascimento, C. W. A.; Biondi, C. M. Produtividade e composição mineral de plantas de milho em solos adubado com lodo de esgoto. Revista Brasileira de Engenharia Agrícola Ambiental, v.11, p.459-465, 2007.

Lobo, T. F.; Grassi Filho, H. Níveis de lodo de esgoto na produtividade do girassol. Journal Soil Science and Plant Nutricion, v.7, p.16-25, 2007.

Malavolta, E.; Vitti, G. C.; Oliveira, S. A. Avaliação do estado nutricional das plantas: Princípios, métodos e técnicas de avaliação do estado nutricional. 2.ed. Piracicaba: Potafos, 1997. 319p.

Melo, L. C. A.; Silva, C. A.; Dias, C. A. Caracterização da matriz orgânica de resíduos de origens diversas. Revista Brasileira de Ciência do Solo, v.32, p.101-110, 2008.

Oliveira, J. P. B. de; Lopes, J. C.; Alexandre, R. S.; Jasper, A. P. dos S.; Santos, L. N. da S.; Oliveira, L. B. de. Efeito do lodo de esgoto no desenvolvimento inicial de duas cultivares de mamona em dois tipos de solos. Engenharia Ambiental, v.6, p.174-180, 2009.

Plachá, I.; Venglovsky, J.; Makova, Z.; Martinez, J. The elimination of Salmonella typhimurium in sewage sljudge by aerobic mesophilic stabilization and lime hydrated stabilization. Bioresource Technology, v.99, p.4269-4274, 2008.

Prestes, R. A.; Colnago, L. A.; Forato, L. A.; Vizzotto, L.; Novotny, E. H.; Carrilho, E. Rapid and atomated low resolution NMR method to analyze oil quality in infact oilseeds, Analítica Chimica Acta, 596, p.325-329. 2007.
Raij, B. van.; Cantarella, H.; Quaggio, J. A; Furlani, A. M. C. Recomendações de adubação e calagem para o estado de São Paulo. 2.ed. Campinas: IAC, 1997. 198p. Boletim Técnico, 100

Rathod, P. H.; Pastel, J. C.; Shah, M. R.; Jhala, A. J. Recicling gamma irradiated sewage sludge as fertilizer: A case study using onion (Allium ceppa). Applied Soil Ecology, v.41, p.223-233, 2009.

Rodrigues, G. B. Maltoni, K. L.; Cassiolato, A. M. R. Dinâmica da regeneração do subsolo de áreas degradadas dentro do bioma cerrado. Revista Brasileira de Engenharia Agrícola Ambiental, v.11, p.73-80, 2007.

Silva, F. C.; Boareto A. E. ; Berton, R. S.; Zotelli, H. B.; Pexe, C. A.; Bernardes, E. M. Efeito do lodo de esgoto na fertilidade de um argissolo vermelho amarelo cultivado com cana de açúcar. Pesquisa Agropecuária Brasileira, v.36, p.831-840, 2001.

Smiderle, O. J.; Gianluppi, D.; Gianluppi, V. Adubação nitrogenada, espaçamento e época de semeadura de girassol nos Cerrados de Roraima. In: EMBRAPA. Resultados de pesquisa da Embrapa Soja-2001: Girassol e trigo. Londrina: Embrapa Soja, 2002. p.33-39. Documentos, 218

Souza, N. C. de; Mota, S. B.; Bezerra, F. M. L.; Aquino, B. F. de; Santos, A. B. dos. Produtividade da mamona irrigada com esgoto domestico tratado. Revista Brasileira de Engenharia Agrícola Ambiental, v.14, p.478-484, 2010.

Terhoven-Urselmans, T.; Schelleer, E.; Raubuch, M. Ludming, B.; Joergensen, R. G. $\mathrm{CO}_{2}$ evolution and $\mathrm{N}$ mineralization after biogas slurry application in the field and its yield effects on spring barley. Applied Soil Ecology, v.42, p.297-302, 2009.

Trannin, I. C. de B.; Siqueira, J. O.; Moreira, F. M. S. Atributos químicos e físicos de um solo tratado com biossolido industrial e cultivado com milho. Revista Brasileira de Engenharia Agrícola Ambiental, v.12, p.223-230, 2008. 